\title{
HPTLC Analysis and Antiproliferative Effect of Various Extracts of Swertia alata on Growth of Leishmania donovani Promastigotes in vitro
}

\author{
Sakshi Bajaj ${ }^{1 *}$, Sharad Wakode², Washim Khan³
}

\section{Sakshi Bajaj ${ }^{1 *}$, Sharad Wa- kode $^{2}$, Washim Khan ${ }^{3}$}

'Department of Pharmacognosy and phytochemistry, University of Delhi, DIPSAR, Sec-III, Pushp Vihar, M.B Road, Delhi-110017, INDIA.

2Professor, Department of Pharmaceutical Chemistry, University of Delhi, DIPSAR, Sec-III, Pushp Vihar, M.B Road, Delhi-110017, INDIA.

${ }^{3}$ Ph.D Scholar, Faculty of Pharmacy, Department of Pharmacognosy and phytochemistry, Jamia Hamdard (Hamdard University), Hamdard Nagar, New Delhi - 110062, INDIA.

\section{Correspondence}

\section{Ms. Sakshi Bajaj}

Department of Pharmacognosy and phytochemistry, University of Delhi, DIPSAR, Sec-III, Pushp Vihar, M.B Road, Delhi-110017, INDIA.

\section{Tel: 09999890085}

E-mail: Sakshibajaj84@gmail.com

\section{History}

- Submission Date: 11-08-2017;

- Review completed: 11-09-2017;

- Accepted Date: 02-11-2017

\section{DOI : 10.5530/pj.2017.6s.166}

Article Available online

http://www.phcogj.com/v9/i6s

\section{Copyright}

(C) 2017 Phcog.Net. This is an openaccess article distributed under the terms of the Creative Commons Attribution 4.0 International license.

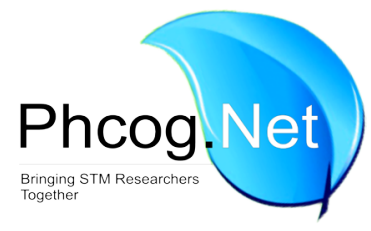

\begin{abstract}
The present study was carried out to evaluate the quality control analysis and antiproliferative effects of petroleum ether, chloroform, ethanol and aqueous extracts of Swertia alata (family Gentianaceae) on Leishmania donovani. A basic, exact, quick and reproducible high performance thin layer chromatography (HPTLC) has been created for synchronous analysis of Oleanolic acid and Swertiamarin from S. alata. The method was validated for linearity, precision, specificity, accuracy and robustness. Densitometric scanning of the plates directly at $254 \mathrm{~nm}$ was used for analysis of Swertiamarin, while as for the analysis of Oleanolic acid; plates were scanned for $520 \mathrm{~nm}$ after spraying with anis aldehyde-sulphuric acid reagent. For the extract of plants and Amphotericin $B$, the concentration response curve was plotted and $I C_{50}$ values were determined and also MTT assay was carried out for comparative study. Compact bands of Oleanolic acid and Swertiamarin were obtained at $R_{f} 0.62 \pm 0.001$ and $0.66 \pm 0.002$, linearity was satisfactory for oleanolic acid and swertiamarin. The developed and validated HPTLC methods were having Linearity range 200-2000 and 100-2000 ng/spot for oleanolic acid and swertiamarin respectively with $r^{2}$ value $0.989 \pm 0.003$ and $0.999 \pm 0.03$, limit of detection (11.25 and $6.19 \mathrm{ng} / \mathrm{spot}$ ), limit of quantification (37.51 and $20.64 \mathrm{ng} / \mathrm{spot}$ ), recovery $(98.4-101.0 \%$ and 98.2-100.8\%) and precision with \% RSD $<2 \%$. Various dried extracts were found to contain oleanolic acid in the range of $0.009 \%-0.012 \%$ and swertiamarin in the range of $0.113-0.135 \%$ $(w / w)$. Cytotoxicity assay of extracts over promastigotes showed that ethanolic extract was found to be most cytotoxic $\left(I C_{50} 31.43 \pm 1.90 \mu \mathrm{g} / \mathrm{mL}\right)$ after $96 \mathrm{~h}$ in comparison to other extracts. The ethanolic extract showed significant reduction in promastigotes which may be due to presence of oleanolic acid as compared with the other groups. The present HPTLC method is being reported for the first time and can be used for routine quality control.
\end{abstract}

Key words: Antiproliferative, HPTLC, Oleanolic acid, Quality control, Swertiamarin.

\section{INTRODUCTION}

The genus Swertia belongs to family gentianaceae which is known to have about 700 species and 80 genera. ${ }^{1}$ Plants belonging to this family are found in all parts of world. They have been widely used in folk medicine. Xanthones derivatives, flavonoids, irridoid glycosides, triterpenoids and dimeric xanthones have been isolated from the genus Swertia., ${ }^{2,3}$ The genus are well known bitter tonic used against loss of appetite and fewer their bitter taste can be attributed to their content of xanthones and irridoids. ${ }^{4}$ The most potential specie Swertia genus (S. chirata) is now nearly extinct from India. S. alata is being used as its replacement, and it has been reported to have Oleanolic acid and Swertiamarin. ${ }^{5}$

Oleanolic acid (3 $\beta$-hydroxyolean-12-en-28-oic acid) is a pentacyclic triterpenoid derived from the isopentenyl pyrophosphate derived from the mevalonate pathway. ${ }^{6}$ It is widely spreaded throughout the plant kingdom. This compound and its derivatives possess several interesting pharmacological activities, such as anti-inflammatory, antioxidant, anticancer, and hepatoprotective effects. ${ }^{7}$ Swertiamarin is a dominant through mevalonic acid pathway. It is distributed predominantly among the members of Gentianaceae, mainly S. chirata and E. littorale. Some specific activities have been reported for swertiamarin such as anticholinergic, ${ }^{8}$ antihyperlipidemic,, 10 insulinotropic, ${ }^{11,12}$ antinociceptive, ${ }^{13}$ antioxidant and hepatoprotective. ${ }^{14}$ Oleanolic acid and swertiamarin are very important bioactive constituents of $S$. alata; therefore, there is an urgent need to develop a simple method for estimation of two chemotherapeutic compound using sophisticated instruments like high performance liquid chromatography (HPTLC). Till date, several analytical methods have been reported for analysis of these both the compounds. However, literature survey shows no single quantitative method available for estimation of both the compounds in the plant S. alata. secoiridoid glycoside derived from loganic acid

Cite this article: Bajaj S, Wakode S, Khan W. HPTLC Analysis and Antiproliferative Effect of Various Extracts of Swertia alata on Growth of Leishmania donovani Promastigotes In vitro. Pharmacog J. 2017;9(6)Suppl:s107-s16. 
Leishmaniasis is a wide spread life-threatening disease which is caused by obligate intracellular, kinetoplastid protozoa of the genus Leishmania. ${ }^{15}$ It is considered one of the serious tropical diseases in many countries. The drugs available for the treatment of leishmaniasis are, in general, toxic, expensive and require long term treatment. There is an inclusive lack of effective and inexpensive chemotherapeutic agents for treatment of Leishmaniasis. Pentamidine is very toxic but still is being used as first choice for the treatment of leishmaniasis because other drugs have shown varying degrees of resistance and efficacy against the Protozoa parasitic. ${ }^{16}$ These drugs are unsatisfactory because of their limited efficacy, frequent side effects and increasing drug resistance therefore, new, safer and more efficacious drugs are urgently required. ${ }^{17}$ Moreover, there is no effective vaccine against leishmaniasis. ${ }^{18}$ In this regard, the selection of bioactive molecules is initiated by a specific screening of plant extracts, isolation by activity directed fractionation and identification of the active compounds.

Swertia alata Royle (Gentianaceae) is one of the common adulterants of $S$. chirata, which is widely used in indigenous medicine as a bitter tonic, febrifuge, laxative, antimalarial, anti-inflammatory, antioxidant and anthelmintic. ${ }^{19,20}$ Several species of Swertia are being used as substitutes or adulterants of $S$. chirata and are known for their therapeutic potential against fever, hepatitis, cholecystitis, pneumonia, osteomyelitis, dysentery, scabies, spasm, pain and malaria. ${ }^{21}$

The present investigation was designed to carry out with an objective of developing a validated sensitive and fast HPTLC method for simultaneous determination and quantification of oleanolic acid and swertiamarin and the extracts were further evaluated to investigate the antiproliferative effect of polar [ethanol (ETSA) and aqueous (AQSA)] and nonpolar compound enriched fractions [petroleum ether (PESA) (fat-rich fraction), chloroform (CHSA) terpenoid and flavonoid-rich fraction] against L. donovani. Analysis of these compounds was carried out using newly developed HPTLC method. The proposed method was developed as per the International Conference on Harmonization ICH guidelines. ${ }^{22,23}$

\section{MATERIAL AND METHODS}

\section{Plant material and chemicals}

The dried plant material was supplied by Almas Pharmaceutical Ltd, Uttar Pradesh and identified by Dr. H.B Singh, Scientist F and Head, Raw Material Herbarium and Museum, NISCAIR (National Institute of Science Communication and Information Resources) Pusa Gate, New Delhi. The voucher specimen (NISCAIR/RHMD/2013/2185/191) of the test drug has been deposited in the herbarium of NISCAIR for future reference. Standard Swertiamarin (Purity: 95.4\% w/w) and Oleanolic acid (Purity: 98.8\% w/w) were purchased from Natural remedies Pvt. Ltd, Bangalore, India. 3-(4, 5 - dimethylthiazol-2-yl)-5-(3carboxymethoxyphenyl)-2-(4-sulfophenyl)-2H-tetrazolium (MTT) was procured from Sigma-Aldrich, USA. Tobie medium, amphotericin B and dimethyl sulfoxide (DMSO) were of molecular biology grade. Precoated silica gel $60 \mathrm{~F}_{254}$ HPTLC plates were purchased from E. Merck, Germany. All the solvents used were of chromatography grade and other chemicals used were of analytical reagent (AR) grade.

\section{Extraction}

The aerial parts of the plant were air dried under shade and then ground to a coarse powder using a mixer. Ground plants material (500 gms) was extracted successively by petroleum ether, chloroform, ethanol and distilled water in soxhlet apparatus. After filtration, the solvent was evaporated to dryness under reduced pressure at a temperature lower than $40^{\circ} \mathrm{C}$ in rota evaporator (Heidolph, Germany). Each time before extraction with next solvents, the coarse powdered material was dried in hot air oven below $50^{\circ} \mathrm{C}$. All the dried extracts were kept in well closed containers under refrigeration until used for the biological testing.

\section{Preparation of standard and quality control (QC) samples}

Stock solutions of Oleanolic acid and Swertiamarin $(10 \mathrm{mg} / \mathrm{mL})$ were prepared in HPLC grade methanol and by appropriate dilution standard solutions were prepared in the concentration range of 0.1 to $1.0 \mathrm{mg} / \mathrm{mL}$. Peak area and amounts applied were treated by linear least-squares regression. Each amount was applied six times. Quality control samples at three different quantitative levels of 400,600 and $800 \mathrm{ng} / \mathrm{band}$ were prepared independently of the calibration standards to carry out validation of the method.

Each extracts $(100 \mathrm{mg})$ was dissolved in $10 \mathrm{~mL}$ of HPLC grade methanol in a $10-\mathrm{mL}$ volumetric flask to get $10 \mathrm{mg} / \mathrm{mL}$ solution. These solutions were sonicated and filtered through $0.22 \mu \mathrm{m}$ syringe filter and then used as test solution for HPTLC analysis.

\section{HPTLC instrumentation and experimental conditions}

Analysis was done on a Camag (Muttenz, Switzerland) HPTLC system, comprising a Linomat $\mathrm{V}$ automatic applicator and TLC scanner III. Chromatography was performed using precoated silica gel TLC (E. Merck, Germany) plated $60 \mathrm{~F}_{254}(20 \mathrm{~cm} \times 20 \mathrm{~cm}$ with $0.2 \mathrm{~mm}$ thickness). The plates were activated at $60^{\circ} \mathrm{C}$ for $5 \mathrm{~min}$ prior to chromatography. TLC sampler, fitted with a $100 \mu \mathrm{L}$ syringe and connected to nitrogen gas, was used for sample application and controlled by win CATS software version 1.2.0, CAMAG. The samples were applied in triplicate $(8.0 \mu \mathrm{L}$ each) and were spotted in the form of bands having band width of $4.0 \mathrm{~mm}$. The plates were developed vertically ascending in a twin trough glass chamber (Camag, Switzerland) saturated with respective mobile phase. The optimized chamber saturation time for the mobile phase was $30 \mathrm{~min}$ at room temperature $\left(25 \pm 2^{\circ} \mathrm{C}\right)$. The chromatogram was developed up to $85 \%$ of total TLC plate height. After the development, HPTLC plates were dried in an oven for $5 \mathrm{~min}$ at $60^{\circ} \mathrm{C}$ for complete removal of mobile phase. The wavelengths for fingerprinting were selected, by multiwavelength scanning, showing the highest number of peaks. The quantification of oleanolic acid and swertiamarin in different extracts were carried out for quality control of crude drugs. The Densitometric quantification was done at UV mode at 246 and 540nm with the help of tungsten lamp and deuterium lamps as a radiation source in reflectance mode. The plate was kept in photo-documentation chamber (CAMAG REPROSTAR 3) and captured the images at 254 and $520 \mathrm{~nm}$. The peak numbers with its height and area, peak display, and peak densitogram were recorded.

The quantification of oleanolic acid and Swertiamarin was carried out in two different sets of chromatography for quality control of extracts of S. alata. In the first chromatography set, the stock solutions of oleanolic acid was applied in triplicate in different volumes $(1-10 \mu \mathrm{L})$ on HPTLC plate and eluted using toluene: ethyl acetate: formic acid, 7.3:1:0.5, v/v/v as solvent system. In the second set of chromatography, swertiamarin was applied in triplicate in different volumes $(1-10 \mu \mathrm{L})$ on HPTLC plate and eluted using n-butanol: acetic acid: water, 7.5:1:1.5, v/v/v as solvent system. The quantification was done by scanning the developed chromatograms at $254 \mathrm{~nm}$ for swertiamarin and at $540 \mathrm{~nm}$ for oleanolic acid after derivatisation with anis aldehyde sulphuric acid reagent.

\section{Validation of the method developed}

The newly developed HPTLC method was optimized and validated as per the ICH guidelines Q2 $\left(\mathrm{R}_{1}\right)$ for different parameters like calibration, linearity, precision, accuracy, robustness, specificity, LOD and LOQ. ${ }^{21,22}$

\section{Calibration curve and linearity}

Different volumes $(0.11 \mu \mathrm{L} / \mathrm{spot})$ of the standard solutions (oleanolic acid and swertiamarin) were separately spotted on TLC plates (in triplicate) to obtain different concentrations of oleanolic acid (200-2000 ng/spot) 
and swertiamarin (100-2000 ng/spot) for calibration plots. The data of peak area versus drug concentration were treated by linear least square regression and the concentration range showing best regressions was considered for linearity. ${ }^{22,23}$

\section{Precision}

Precision of the proposed method was obtained by repeatability and intermediate precision. Inter-day and intraday precisions were done by preparing and applying three different concentrations of standards (in triplicate) on the same day and on three different consecutive days, respectively. ${ }^{23}$ The inter instrumental and inter-analyst precision was carried out by repeating the same procedure using different systems of the same make and by different analysts, respectively. Precision studies were done at three different concentration levels. The results were determined and reported in terms of \% RSD. ${ }^{24}$

\section{Robustness of the method}

Robustness of the analytical procedure is a measure of its capacity to remain ineffective by small, but deliberate, variations in the method parameters and provide an indication of its reliability during normal usage. Robustness of the method was achieved by introducing small changes in the compositions of mobile phase and detection wavelength. The effect on the results was reported as $\%$ RSD. ${ }^{23}$

\section{Specificity}

The specificity of the method was ascertained by analysing standard drug and sample. The detection of spots for oleanolic acid and swertiamarin were confirmed by comparing $\mathrm{R}_{\mathrm{f}}$ and spectra of spots with those of the standards. The peak purity was assessed by comparing the spectra at three different levels, i.e. peak start, peak apex and peak end positions of the spot. ${ }^{23}$

\section{Limit of detection (LOD) and limit of quantification (LOQ)}

The LOD was expressed as LOD $=3.3 \sigma$ /slope, whereas LOQ was expressed as $\mathrm{LOQ}=10 \sigma /$ slope of calibration curve, where $\sigma$ is the standard deviation of the response at low concentrations. Slope $=$ the slope of the calibration curve. ${ }^{22}$

\section{Accuracy as recovery}

In analytical methods, the closeness of test results obtained by that method to the theoretical value is called the accuracy. The standard addition method was used by spiking at four different concentration levels, that is, $0,50,100$ and $150 \%$, of analyte in pre-analysed samples. ${ }^{22}$

\section{Estimation of oleanolic acid and swertiamarin in extracts}

The newly developed and validated HPTLC method was applied for the analysis of oleanolic acid and swertiamarin in extracts of S. alata. Oleanolic acid and Swertiamarin were estimated in PESA, CHSA, ETSA and AQSA extract. The samples were applied in triplicate on HPTLC plates with standard and the contents of metabolites were analysed, using regression equations obtained from calibration plots, and expressed as $\%$ w/w. All the extracts showed number of UV active compounds and thus detected at $254 \mathrm{~nm}$ and $540 \mathrm{~nm}$ after visualization with or without derivatisation.

\section{Antiproliferative Assay Leishmania culture}

L. donovani used in this work was cultured promastigote forms which were obtained from the laboratory of National Communicable Disease Control programme (NCDC), New Delhi. Promastigotes were grown in modified Tobie's medium, ${ }^{25}$ which consists of two phases blood agar (solid phase) and Locke's solution (liquid phase), $5 \mathrm{~mL}$ of solid phase was dispensed in to $25 \mathrm{~mL}$ flask, and just before use, $2 \mathrm{~mL}$ of Locke's solution was added to the flask. Then the flask was incubated at $24^{\circ} \mathrm{C}$ for $72 \mathrm{~h}$.
After three days, the mortality was recorded by counting the live promastigotes in Neubauer counting chamber. ${ }^{26}$

\section{Antiproliferative assay of extracts}

The antiproliferative assay of extracts was carried out to find out the best active extract. The stock solutions were prepared by dissolving $500 \mathrm{mg}$ of each extract in $10 \mathrm{~mL}$ DMSO. These solutions were passed through $0.45 \mu \mathrm{M}$ membrane filter and stored at $4^{\circ} \mathrm{C}$ until used. These were diluted Tobie's medium to get a concentration of $1000 \mu \mathrm{g} / \mathrm{mL}$ of every extract. ${ }^{27}$ Further, these solutions were passed through $0.22 \mu \mathrm{M}$ filter under sterile conditions in laminar flow hood before using for in vitro activity on promastigotes. Similarly, DMSO control was also prepared ${ }^{27}$ while amphotericin B was used as the reference standard drug. ${ }^{28}$

Promastigote forms from a logarithmic phase culture were suspended to yield 1 million of cells /mL after Neubauer chamber counting. Each well of 96 well plate was filled with $100 \mu \mathrm{L}$ of the parasite suspension, and the plates were incubated at $24^{\circ} \mathrm{C}$ for $1 \mathrm{~h}$ before drug addiction. ${ }^{29}$

\section{Promastigotes extracts susceptibility assay}

The antileishmanial activity was performed according to a previously described method. ${ }^{30}$ Briefly Promastigotes of $L$. donovani were cultured in Tobie's medium. The viability of promastigotes was assessed by tetrazolium- dye (MTT) colorimetric method. MTT assay was performed on $L$. donovani promastigotes. $1 \times 10^{6}$ parasite $/ \mathrm{mL}$ promastigotes were seeded in 96 well plastic tissue cultures flat plates supplemented with $100 \mu \mathrm{L}$ of the respective culture medium for a period of $24 \mathrm{~h}$ maintained at $24^{\circ} \mathrm{C}$.It was then substituted by $100 \mu \mathrm{L}$ of fresh media containing varying concentrations of the extract $(1000,500,250,125,62.5$ and $31.2 \mu \mathrm{g} / \mathrm{mL})$. The plates were again incubated for $24,48,72$ and $96 \mathrm{~h}$, separately at $37^{\circ} \mathrm{C}$, by changing fresh media containing extracts every $24 \mathrm{~h} .{ }^{31}$ After incubation period media were removed and fresh media added; $20 \mu \mathrm{L}$ of MTT reagent prepared in PBS (Phosphate buffer saline) was then added to all the wells and the plate was re-incubated for $4 \mathrm{~h}$. After seeing purple colour precipitation which was very well visible under microscope, media were carefully discarded for solubilisation of formazan crystals (MTT formazan). Further, $100 \mu \mathrm{L}$ of DMSO was added to each well and cells were incubated in dark at room temperature for $1 \mathrm{~h}$. The purple colour developed and the absorbance was read at $490 \mathrm{~nm}$ by a microplate reader (Bio-Rad, USA). Percentage of inhibition was calculated by comparing the percent viability with untreated control ${ }^{32}$ and percentage promastigote viability was calculated using the formula of Mossman, $1983^{33}$ at each concentration.

Promastigote viability $(\%)=($ Absorbance of control) - (Absorbance of sample)/ Absorbance of control x 100

\section{Statistical analysis}

Data represented as the mean \pm SD of triplicate samples from three independent assays. The $\mathrm{IC}_{50}$ values were calculated using dose-response curves in graph pad prism 5.0 software (California, USA). Data with $\mathrm{p}<0.05$ were accepted as not significantly different.

\section{RESULTS AND DISCUSSION}

The plant material was extracted using successive hot extraction using different solvents (Petroleum ether, chloroform, ethanol and distilled water) separately. The hot extraction was selected for the present study due to its high yields and the yield obtained were PESA (1.968 \%), CHSA (1.613\%), ETSA (7.963\%) and AQSA (9.012\%). 


\section{HPTLC Analysis}

The various extracts were subjected to HPTLC analysis by specific solvent system. The composition of the mobile phase for development of chromatographic method was optimized by testing different solvent mixtures of varying polarity. The mobile phase, toluene: Ethyl acetate: formic acid (7.3:1:0.5) was optimized for separation and quantification of Oleanolic acid in PESA, CHSA, ETSA, AQSA. All the extracts showed good separation with compact spot Figure1. Oleanolic acid was well separated, using the same solvent as indicated above but visualized after derivatization with anis aldehyde sulphuric acid. It was scanned at $520 \mathrm{~nm}$ wavelength, which showed compact peak at $\mathrm{R}_{\mathrm{f}} 0.66 \pm 0.02$ Figure 1 and $2(\mathrm{a})-2(\mathrm{e})$.

The mobile phase n-butanol: acetic acid: Water, 7.5: 1: 1.5v/v/v was optimized for separation and quantification of Swertiamarin in PESA, CHSA, ETSA and AQSA. All the extracts showed good separation with compact spot Figure 3. Swertiamarin was well separated, using the same solvent as indicated without derivatization. It was scanned at $254 \mathrm{~nm}$ wavelength, which showed compact peak at $\mathrm{R}_{\mathrm{f}} 0.62 \pm 0.01$ Figure 3 and 4 (a) - 4(e).

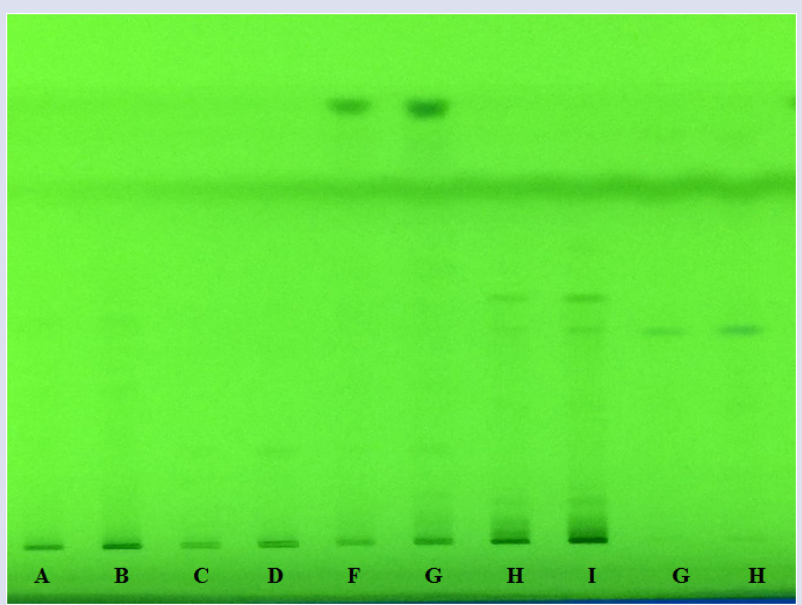

Figure 1: Photodocumentation of (A, B) PESA extract (C, D) CHSA extract (E, F) ETSA extract $(G, H)$ AQSA (I) Swertiamarin $R_{f}$ : $0.66 \pm 0.002$ using $60 \mathrm{~F}-520$ TLC plates, mobile phase $n$-butanol: acetic acid: water, 7.5:1:1.5, v/v/v.

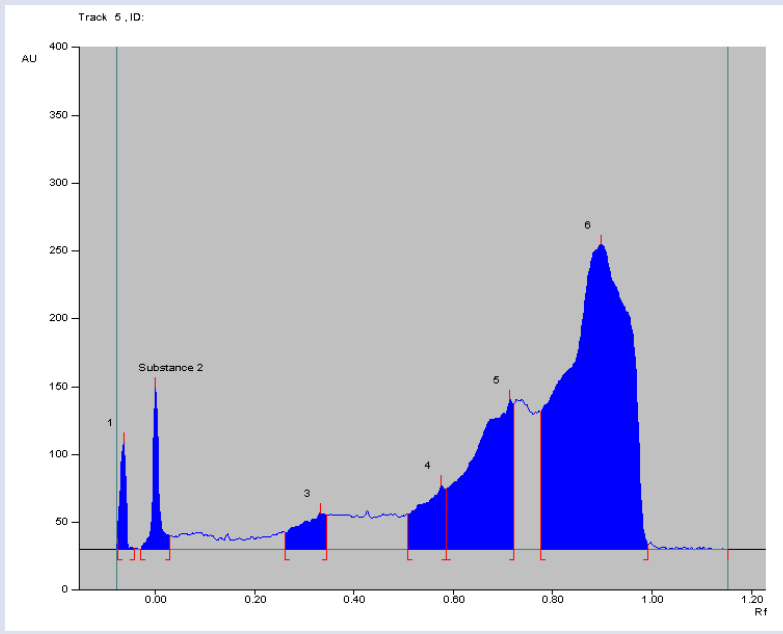

(a)

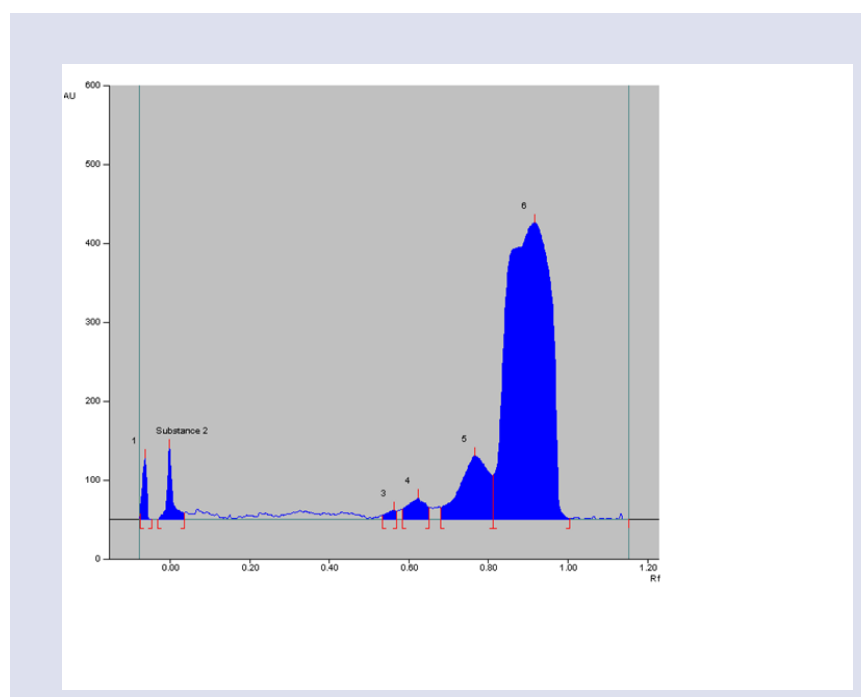

(b)

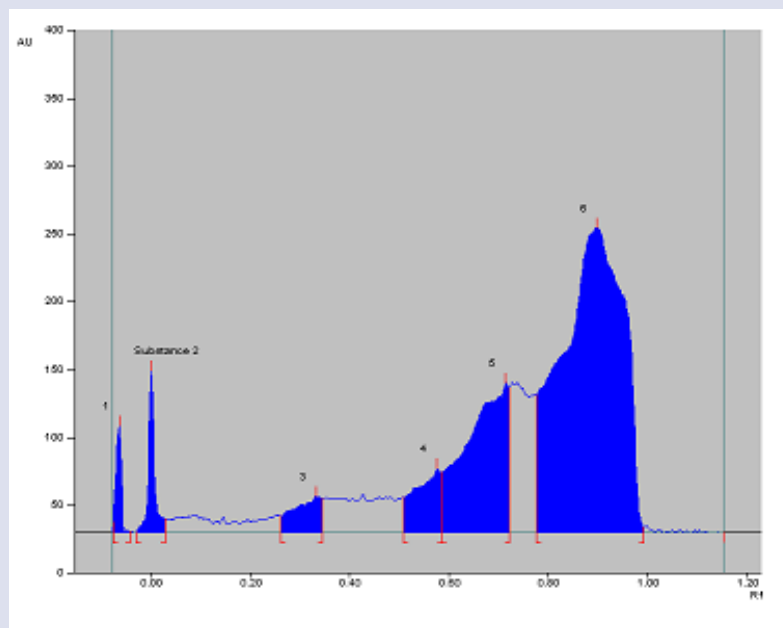

(c)

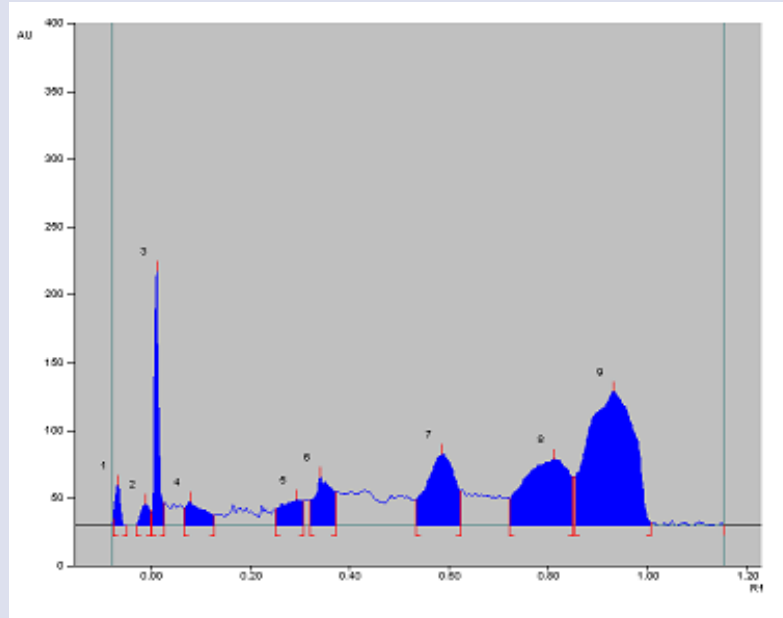

(d) 


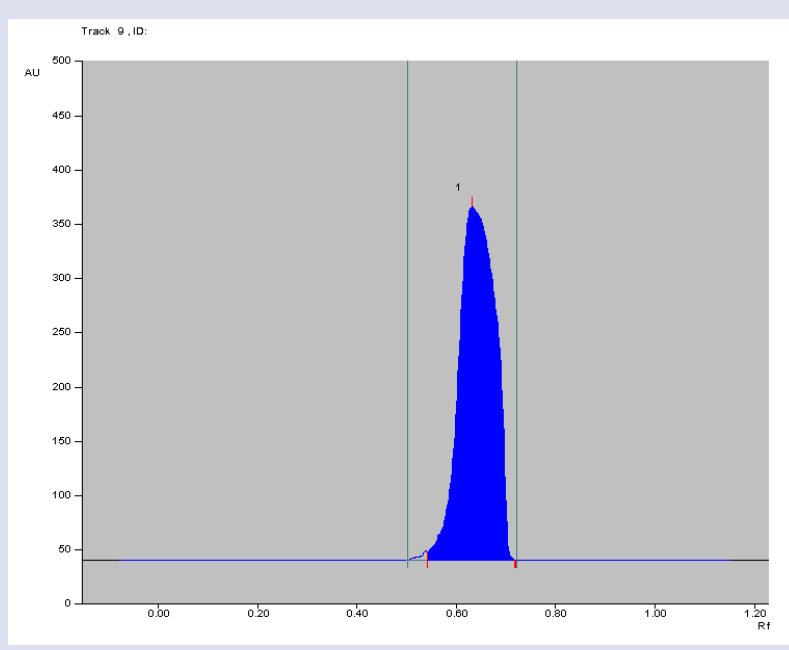

(e)

Figure 2: Developed HPTLC chromatogram a) PESA extract b) CHSA extract c) AQSA extract d) ETSA extract e) Swertiamarin at $254 \mathrm{~nm}$ showing peaks of separated compounds in $n$-butanol: acetic acid: water, 7.5:1:1.5, v/v/v.

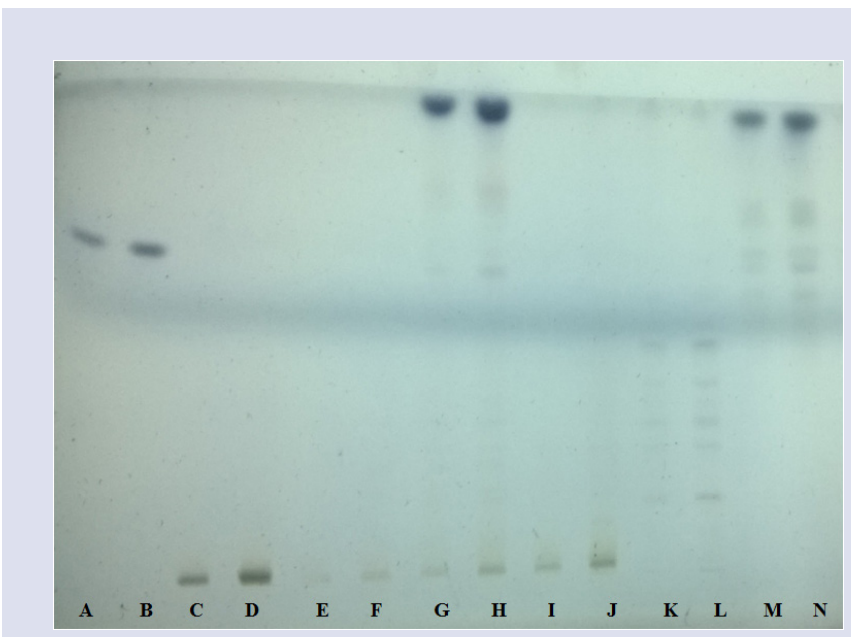

Figure 3: Photo documentation of (A, B) Oleanolic acid $R_{f}: R_{f}$ $0.62 \pm 0.001$ (C, D) PESA extract (E, F) CHSA extract $(G, H)$ ETSA extract (M, N) AQSA using 60F-520 TLC plates, mobile phase toluene: ethyl acetate: formic acid, 7.3:1:0.5, v/v/v after derivatisation with anis aldehyde sulphuric acid.

\section{Validation of the method developed}

\section{Calibration curve and linearity}

The proposed method for simultaneous estimation of oleanolic acid and swertiamarin were found linear for a wide range of concentration with good regression coefficient $(>0.99)$. The linearity was evaluated by data of peak area versus drug concentration and was treated by using linear least-squares regression and the concentration range showing best regressions was considered for its linearity. The regression equation with slope, intercept, and coefficient of correlation $\left(\mathrm{R}^{2}\right)$ was calculated and are given in Table 1.

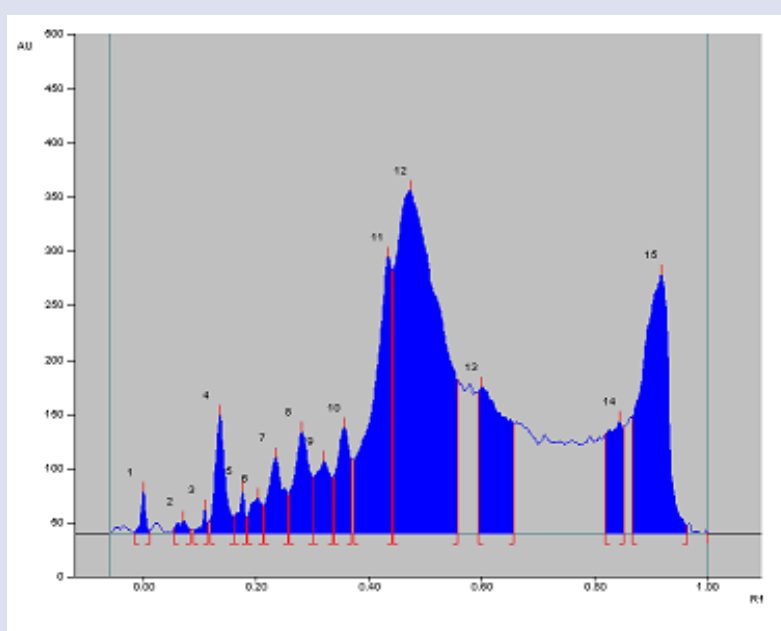

(a)

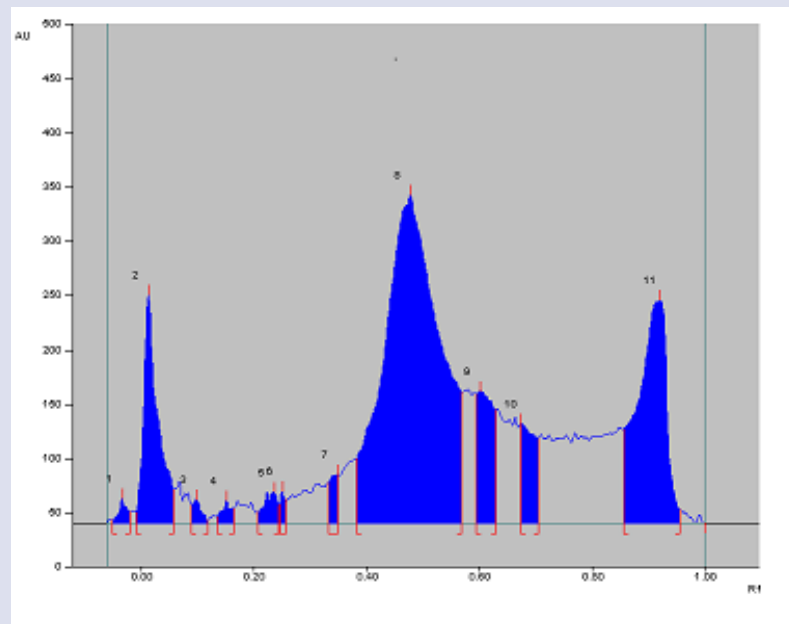

(b)

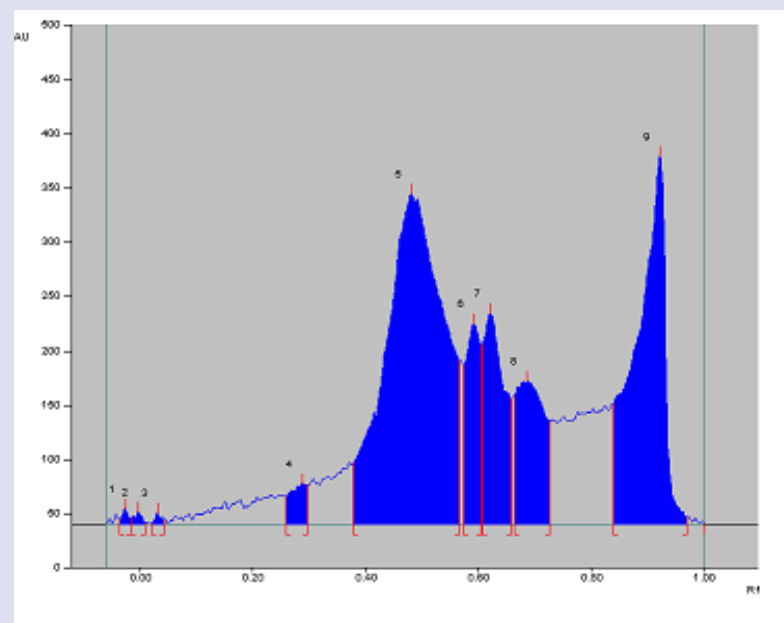

(c) 


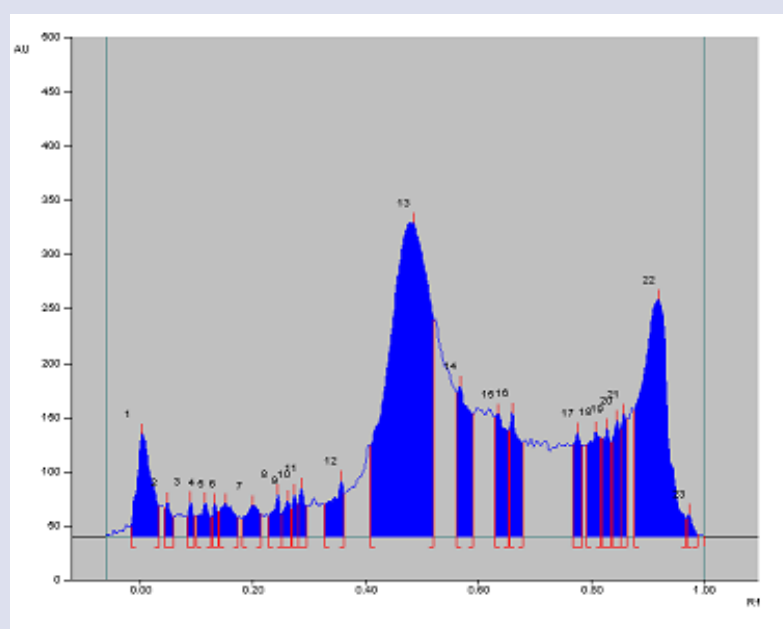

(d)

\section{Precision}

Table 2 represents inter-day and intra-day precision. Precision was checked by preparing and applying inter-day and intraday at three different concentration of standards (in triplicate) i.e. 200, 400 and $600 \mathrm{ng} / \mathrm{spot}$ on the same day and on three different days, respectively. The inter-analyst precision was done by repeating the same procedure using different systems of the same make and by different analyst. Low RSD (\%) values obtained indicated that the method is precise.

\section{Limit of detection (LOD) and limit of quantification (LOQ)}

LOD and LOQ of different markers were calculated as per the standard protocol and reported in Table 1. This indicated that the proposed

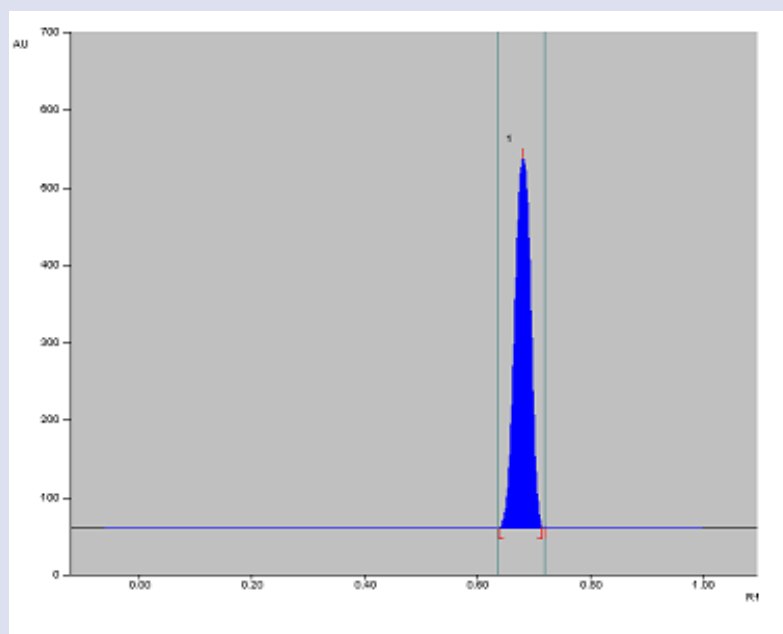

(e)

Figure 4: Developed HPTLC chromatogram a) PESA extract b) CHSA extract c) AQSA extract d) ETSA extract e) Oleanolic acid at $520 \mathrm{~nm}$ showing peaks of separated compounds in toluene: ethyl acetate: formic acid, 7.3:1:0.5, v/v/v.

method exhibits a good sensitivity for the quantification of above compounds.

\section{Accuracy (recovery)}

The accuracy of the method was assessed by spiking 0, 50, 100 and 150\% of analyte in prenasalized samples with known amounts of standard and then re-analysed by the HPTLC method. The \%RSD values after spiking with 50, 100 and $150 \%$ of drug was lying in the range of $98.7-101.0 \%$. The experiment was conducted in triplicate Table 3.

Table 1: Linearity data of chromatographic HPTLC method for oleanolic acid and swertiamarin ( $n=6)$.

\begin{tabular}{|c|c|c|c|c|c|c|c|c|}
\hline Biomarkers & Solvent System & $\begin{array}{l}\text { Linearity } \\
\text { (ng spot }^{-1} \text { ) }\end{array}$ & Equation & $\begin{array}{c}\text { Regression } \\
\pm \text { SD }\end{array}$ & Slope \pm SD & Intercept \pm SD & $\begin{array}{c}\text { LOD } \\
\left(\text { ng spot }^{-1}\right)\end{array}$ & $\begin{array}{c}\text { LOQ } \\
\left.\text { (ng spot }{ }^{-1}\right)\end{array}$ \\
\hline Oleanolic acid & $\begin{array}{c}\text { (Toluene: Ethyl } \\
\text { acetate: Formic } \\
\text { acid,7:3:1:0.5, } \\
\text { v/v/v/v) }\end{array}$ & $\begin{array}{c}200 \\
-2000\end{array}$ & $Y=10.65 X+4751.4$ & $0.989 \pm 0.003$ & $10.65 \pm 0.045$ & $4825.6 \pm 2.54$ & 11.25 & 37.51 \\
\hline Swertiamarin & $\begin{array}{l}\text { n-butanol: acetic } \\
\text { acid: water, } \\
7.5: 1: 1.5, \mathrm{v} / \mathrm{v} / \mathrm{v})\end{array}$ & $\begin{array}{l}100- \\
2000\end{array}$ & $\mathrm{Y}=12.46 \mathrm{X}+3767.8$ & $0.999 \pm 0.03$ & $12.45 \pm 0.02$ & $3845.5 \pm 5.62$ & 6.19 & 20.64 \\
\hline
\end{tabular}

Table 2: Precision of the method for the estimation of oleanalic acid and swertiamarin $(n=6)$.

\begin{tabular}{|c|c|c|c|c|c|c|}
\hline \multirow{2}{*}{$\begin{array}{c}\text { Conc. } \\
\left.\text { (ngspot- }{ }^{-1}\right)\end{array}$} & \multicolumn{2}{|c|}{ Inter-day precision } & \multicolumn{2}{|c|}{ Intra-day precision } & \multicolumn{2}{|c|}{ Inter-analyst precision } \\
\hline & $\begin{array}{c}\text { Mean peak area } \\
\pm S \text {. D }\end{array}$ & $\%$ RSD & $\begin{array}{c}\text { Mean peak area } \\
\pm \text { S. D }\end{array}$ & $\%$ RSD & $\begin{array}{c}\text { Mean peak area } \\
\pm S \text {. D }\end{array}$ & $\%$ RSD \\
\hline & & & Oleanolic acid & & & \\
\hline 400 & $8897.4 \pm 21.5$ & 1.4 & $8925.5 \pm 21.5$ & 1.8 & $8869.4 \pm 35.6$ & 1.9 \\
\hline 600 & $11458.5 \pm 28.9$ & 1.1 & $11365.4 \pm 35.6$ & 1.7 & $11658.7 \pm 41.2$ & 1.4 \\
\hline \multirow[t]{2}{*}{800} & $13586.4 \pm 34.6$ & 0.8 & $13456.6 \pm 41.6$ & 1.7 & $13687.4 \pm 52.6$ & 1.1 \\
\hline & & & Swertiamarin & & & \\
\hline 400 & $8994.5 \pm 21.5$ & 1.9 & $8874.5 \pm 25.4$ & 2.0 & $8874.5 \pm 25.7$ & 1.8 \\
\hline 600 & $11654.6 \pm 29.5$ & 1.6 & $11789.6 \pm 31.5$ & 1.9 & $11485.6 \pm 32.5$ & 1.7 \\
\hline 800 & $13654.5 \pm 35.9$ & 1.7 & $13458.4 \pm 35.3$ & 1.7 & $13458.4 \pm 41.5$ & 0.8 \\
\hline
\end{tabular}


Table 3: Accuracy of the HPTLC methods for the estimation of oleanolic acid and swertiamarin.

\begin{tabular}{|cccc|}
$\begin{array}{c}\text { Theoretical content } \\
\left(\mu \mathrm{g} \mathrm{mL} \mathrm{m}^{-1}\right)\end{array}$ & $\begin{array}{c}\text { Amount of drug } \\
\text { recovered }\left(\mu \mathrm{g} \mathrm{m}^{-1}\right)\end{array}$ & $\begin{array}{c}\text { \% of drug } \\
\text { recovered }\end{array}$ & \% RSD \\
\hline $\begin{array}{c}\text { Oleanolic acid } \\
50\end{array}$ & 50.5 & 101.0 & 0.7 \\
112 & 110.5 & 98.6 & 0.7 \\
225 & 220.4 & 98.4 & 0.8 \\
Swertiamarin & & & \\
175 & 173.0 & 98.8 & 0.7 \\
300 & 302.4 & 100.8 & 0.9 \\
525 & 515.6 & 98.2 & 0.8 \\
\hline
\end{tabular}

Table 4: Robustness of the HPTLC method for estimation of Oleanolic acid and Swertiamarin by changing detecting of wavelengths.

\begin{tabular}{|c|c|c|c|c|}
\hline \multicolumn{3}{|c|}{ Parameters } & \multirow[b]{2}{*}{$\begin{array}{c}\text { Mean area } \\
\quad \pm \text { SD }\end{array}$} & \multirow[b]{2}{*}{$\begin{array}{c}\% \text { RSD of } \\
\text { area }\end{array}$} \\
\hline Components & $\begin{array}{c}\text { Conc. } \\
\left(\text { ng spot }^{-1}\right)\end{array}$ & $\begin{array}{c}\text { Wavelength } \\
\text { used }\end{array}$ & & \\
\hline \multirow{4}{*}{ Oleanolic acid } & 400 & 535 & $8798.5 \pm 18.5$ & 2.0 \\
\hline & & 545 & $88.45 .4 \pm 18.0$ & 2.0 \\
\hline & 600 & 535 & $11547.5 \pm 25.6$ & 1. \\
\hline & & 545 & $11654.4 \pm 28.4$ & 1.7 \\
\hline \multirow{8}{*}{ Swertiamarin } & 800 & 535 & $13589.6 \pm 425$ & 1.1 \\
\hline & & 545 & $13689.4 \pm 43.8$ & 1.0 \\
\hline & 400 & 535 & $8945.5 \pm 19.55$ & 1.9 \\
\hline & & 545 & $8856.4 \pm 19.7$ & 1.9 \\
\hline & 600 & 535 & $11578.8 \pm 21.0$ & 1.6 \\
\hline & & 545 & $11658.8 \pm 19.5$ & 1.7 \\
\hline & 800 & 535 & $136333 \pm 26.3$ & 1.9 \\
\hline & & 545 & $13683.4 \pm 27.6$ & 2.0 \\
\hline
\end{tabular}

Table 5: Estimation of oleanolic acid and swertiamarin in different extracts of S. alata.

\begin{tabular}{ccccc}
\hline Marker & \multicolumn{4}{c}{$\mathrm{mg} / \mathrm{g}$ of dried extract } \\
\hline & PESA & ETSA & CHSA & AQSA \\
Oleanolic acid & 0.2 & 5.0 & 3.4 & 3.2 \\
Swertiamarin & 1.4 & 24.4 & 12.4 & 31.4 \\
\hline
\end{tabular}

\section{Robustness}

The low values of $\%$ RSD $(<2.0)$ obtained after introducing small deliberate changes in experimental conditions like change in wavelength at concentrations of 400,600 and $800 \mathrm{ng} /$ spot in triplicate indicated the robustness of the method. The results were expressed as \% RSD Table 4.

\subsubsection{Estimation of oleanolic acid, swertiamarin in various extracts of S. alata}

The newly developed and validated HPTLC method was applied for the simultaneous estimation of oleanolic acid and swertiamarin in various extracts of S.alata. The amount of oleanolic acid in various extract of drug i.e. PESA, ETSA, CHSA, and AQSA was found to be $0.02 \% \mathrm{w} / \mathrm{w}$, $0.05 \% \mathrm{w} / \mathrm{w}, 0.34 \% \mathrm{w} / \mathrm{w}$ and $0.32 \% \mathrm{w} / \mathrm{w}$ and swertiamarin found to be $0.14 \% \mathrm{w} / \mathrm{w}, 2.44 \% \mathrm{w} / \mathrm{w}, 1.24 \% \mathrm{w} / \mathrm{w}$ and $3.14 \% \mathrm{w} / \mathrm{w}$ respectively Table 5.

\section{Antiproliferative assay of S. alata}

Determining the absence of toxic effects on host cells is an important criterion that must be evaluated when searching for active compounds

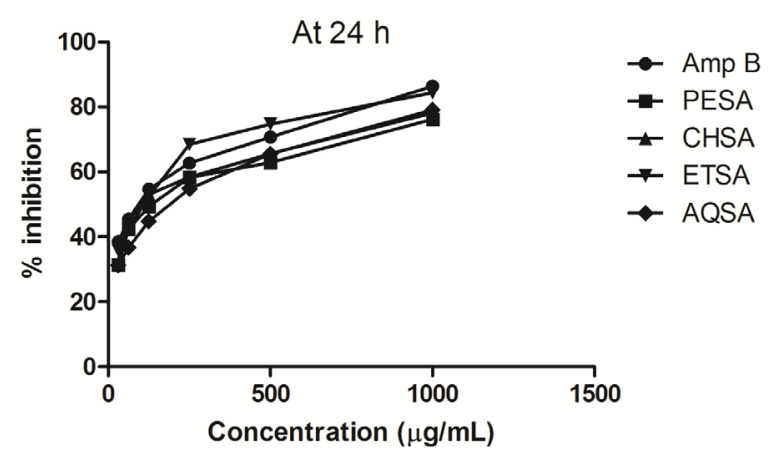

(a)

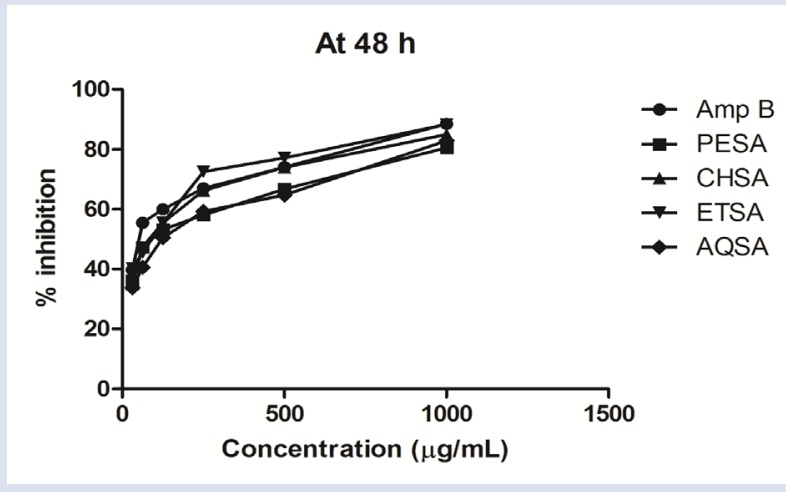

(b)

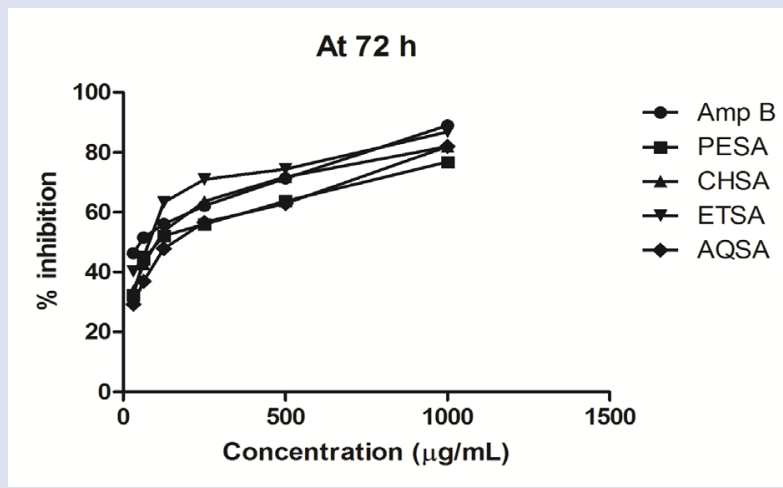

(c)

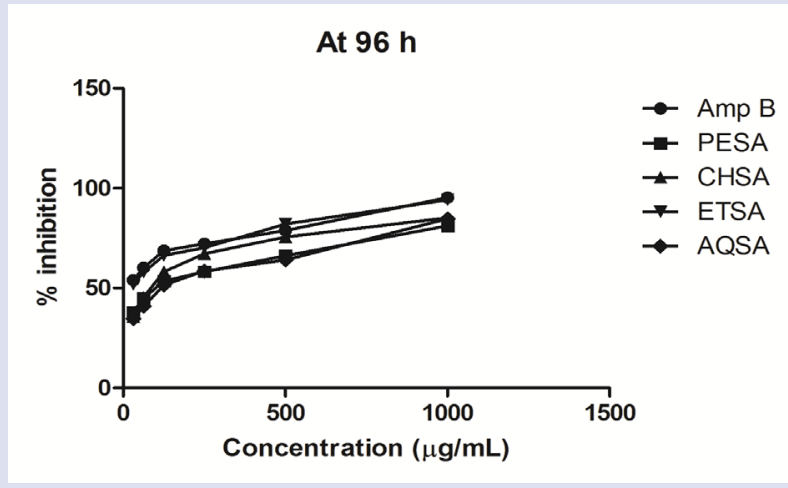

(d)

Figure 5: Showing percentage inhibition of promastigotes of L. donovani at $24,48,72$ and $96 \mathrm{~h}$. 


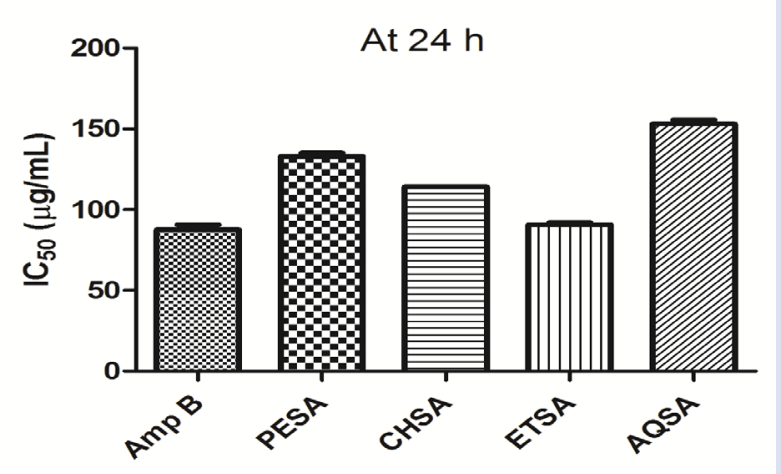

(a)

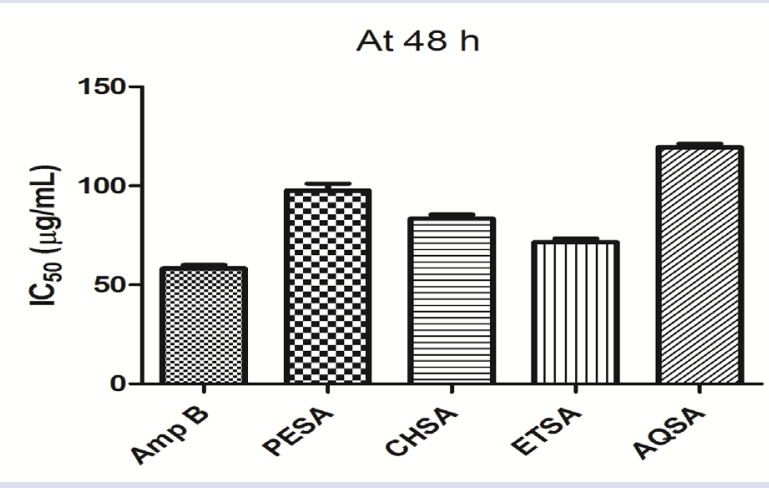

(b)

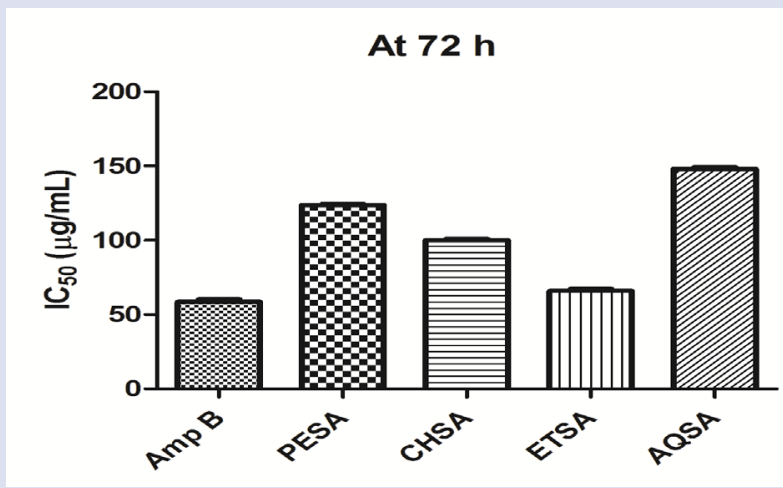

(c)

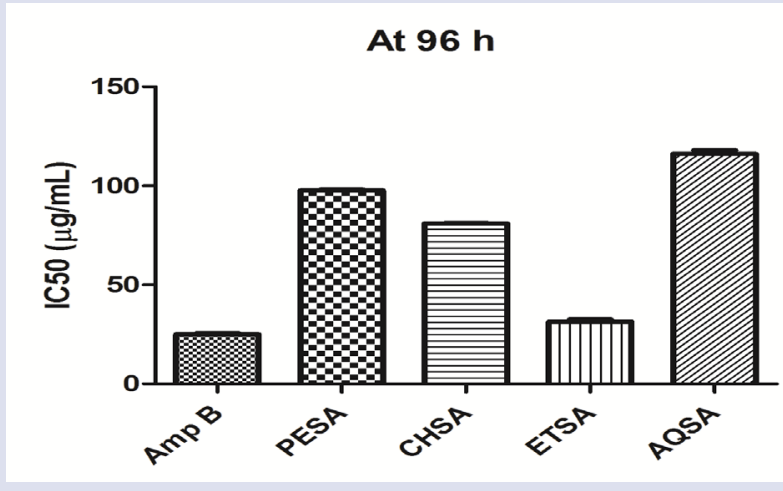

(d)

Figure 6: Showing $I C_{50}$ of extracts at $24,48,72$ and $96 \mathrm{~h}$. with therapeutic potential against $L$. donovani. Up to $1 \%(\mathrm{v} / \mathrm{v}), \mathrm{DMSO}$ had no effect on parasite growth rate and mobility morphology. ${ }^{29}$ The extracts of plants and drug inhibited the growth of promastigote forms of L. donovani in vitro after $24,48,72$ and $96 \mathrm{~h}$ of incubation and had a $50 \%$ inhibitory concentration $\left(\mathrm{IC}_{50}\right.$ ) that were shown in Figure 4 . The $\mathrm{IC}_{50}$ values were computed by entering the optical density readings in a preset MS excel template. The $\mathrm{IC}_{50}$ values for the PESA, CHSA and AQSA extracts for $L$. donovani were significantly different $(\mathrm{p}<0.001)$ while in case of ETSA extract it was not significant statistically as compared to the standard Amphotericin B ( $\mathrm{p}>0.05)$. From the determined $\mathrm{IC}_{50}$ values and percentage of inhibition of promastigote number with the increase of concentration through different growth periods $24,48,72$ and $96 \mathrm{~h}$, the concentration dependent effect of extract was shown in Figure 5.

The results of antileshmaniac activity exhibited that extracts of $S$. alata are having antileshmaniac activity. In the preliminary study, the extracts exhibiting $>40 \%$ inhibition at the tested concentrations, were considered to have high antileishmanial potential, and are tested further on the L. donovani macrophage infection assay. ${ }^{34}$ The ETSA exhibited the highest inhibition percentage of $L$. donovani promastigote $(94.17 \pm 1.54 \%)$ at $1000 \mu \mathrm{g} / \mathrm{mL}$ and $(82.12 \pm 0.45 \%)$ at half of this concentration at $96 \mathrm{~h}$. Additionally, CHSA, PESA and AQSA extracts showed inhibition of approximately $50 \%$ at $500 \mu \mathrm{g} / \mathrm{mL}$, and there was $5-10 \%$ reduction of the inhibition percentage at half of this concentration at 96h Figure 6. All the selected plants extracts were shown active or significant active at the lowest tested concentration $(50 \mu \mathrm{g} / \mathrm{mL})$. The L. donovani promastigotes treated with ETSA extract had the highest viability at all concentrations followed by CHSA. The gradual decrease in the number of promastigotes indicates that there is a clear toxic effect of the ethanolic extract as compared with all other extracts. There is a proportional relation between the concentration of the extract and its inhibitory effect. The genus Swertia has a wide range of uses in traditional medicine. To the best of our knowledge, no previous report was available regarding the evaluation of $S$. alata as antileishmanial activity against $L$. donovani.

In the present study, it was found that the antileishmanic activity of the ETSA extract of $S$. alata was very effective at $96 \mathrm{~h}$ and showed similar results like the control i.e. amphotericin $B$. The opinion to the strong effect of S. alata on L. donovani promastigote may be due to presence of secoiridoid glycoside and oleanolic acid in this plant, which was reported previously with the same genus and different species. ${ }^{35,36}$

\section{CONCLUSION}

Our results suggest that ethanolic fraction of $S$. alata might be a good candidate for development as antileishmanic drug and may come out as a new future phytopharmaceutical drug. In addition, a validated method was developed for quantification of oleanolic acid and swertiamarin in various fractions of extracts that can be used for its quality control as well as for that of other drugs containing them as ingredient. The analysis of two marker compounds for the quality control of various fraction using HPTLC methods in present investigation is unique and being reported for the first time.

Based on this study, S. alata could be considered as a potential candidate of leishmanicidal drug against $L$. donovani. Thus, more investigations should be done, first In vitro assay for finding anti-leishmanial effect by using Leishmania amastigote and then to investigate In vivo activity in laboratorial infected animals. This would help in obtaining a novel drug that could potentially be less toxic and more cost effective against the leishmania parasite. This is a first report of work carried out on the antileishmanial effects of this plant so far. Further urgent attention and research is needed for making this drug available soon before the epidemic of leishmaniasis rises further, however no work has been reported till date for antileishmanial activity of $S$. alata. 


\section{CONFLICT OF INTEREST}

We declare that we have no conflict of interest.

\section{ACKNOWLEDMENT}

The present work was completed in DIPSAR, Delhi. Authors are highly thankful to the Director Dr. D.P Pathak for providing the research facilities.

\section{REFERENCES}

1. Handa KL. A modified method for the assay of Swertia chirata. Indian journal of pharmaceutical sciences. 1952;14:87-8.

2. Tan P, Hou C, Liu Y, Lin LJ, Cordell GA. Swertipunicoside. The first bisxanthone C-glycoside. J Org Chem. 1991;56(25):7130-3.

3. Zhou HM, Liu YL, Blasko G, Cordell GA. Sweriabisxanthone-1 from Swertia macrosperma. Phyto chemistry. 1989;28(12):3569-71.

4. Jensen SR, Schripsema J. Chemotaxonomy and pharmacology of gentianaceae systematic and natural history, Cambridge university press. London. 2002.

5. Negi JS, Singh P, Rawat B. Chemical constituents and biological importance of Swertia: A review, current research in chemistry. 2011;3(1):1-15.

6. Yamahara M K, Matsuda H, Aoki S. Anticholinergic action of Swertia japonica and an active constituent. J Ethno-pharmacology. 1991;33(1-2):31-5.

7. Vaidya H, Rajani M, Sudarsanam V, Padh H, Goyal RK. Antihyperlipidaemic activity of swertiamarin, a secoiridoid glycoside in poloxamer-407-induced hyperlipidaemic rats. J Nat Med. 2009;63(4):437-42.

8. Vaidya H, Rajani M, Sudarsanam V, Padh H, Goyal RK. Swertiamarin: A lead from Enicostemma littorale Blume. for anti-hyperlipidaemic effect. Euro J Pharmacology. 2009;617(1):108-12

9. Maroo J, Vasu VT, Aalinkeel R, Gupta SJ. Glucose lowering effect of aqueous extract of Enicostemma littorale Blume in diabetes: a possible mechanism of action. J Ethnopharmacology. 2002;81(3):317-20.

10. Vaidya H, Prajapati A, Rajani M, Sudarsanam V, Padh H, Goyal RK. Anti-diabetic activity of swertiamarin is due to an active metabolite, gentianine, that upregulates PPAR- $\gamma$ gene expression in 3T3-L1 cells. Phytother. Res. 2012;26:1259-61.

11. Jaishree V, Badami S, Kumar RM, Tamizhmani T. Antinociceptive activity of swertiamarin isolated from Enicostemma littorale. Phytomedicine, 2009; 16(2):227-32.

12. Jaishree V, Badami S, Kumar RM. Antioxidant effect and hepatoprotective effect of ethyl acetate extract of Enicostemma axillare (Lam) Raynal against CCl4 induced liver injury in rats. Indian J. Exp. Biol. 2010;48:896-904.

13. Phillips DR, Rasbery JM, Bartel B, Matsuda SPT. Biosynthetic diversity in plant triterpene cyclization, Current. Opinion. Plant Biol. 2006;9(3):305-14.

14. Liu J. Pharmacology of oleanolic acid and ursolic acid, Journal of Ethnopharmacology. 1995;49(2):57-68.

15. World Health Organization. World health report: Report of the consultative meeting on cutaneous leishmaniasis. Geneva, Switzerland: World Health Organization. 2008.

16. Pant N, Jain DC, Bhakuni RS. Phytochemicals from genus Swertia and their biological activities, Indian journal of Chemistry. 2000;39 B:565-86.

17. Croft SL, Seifert K. Miltefosine: interactions with other antileishmanial drugs. Abstracts of the 3rd World Congress on Leishmaniasis. 2005; pp.10-15. Palermo, Italy:57.

18. Handman E. Leishmaniasis: current status of vaccine development. Clinical Microbiology. Rev. 2001;14(2):229-43.

\section{GRAPHICAL ABSTRACT}

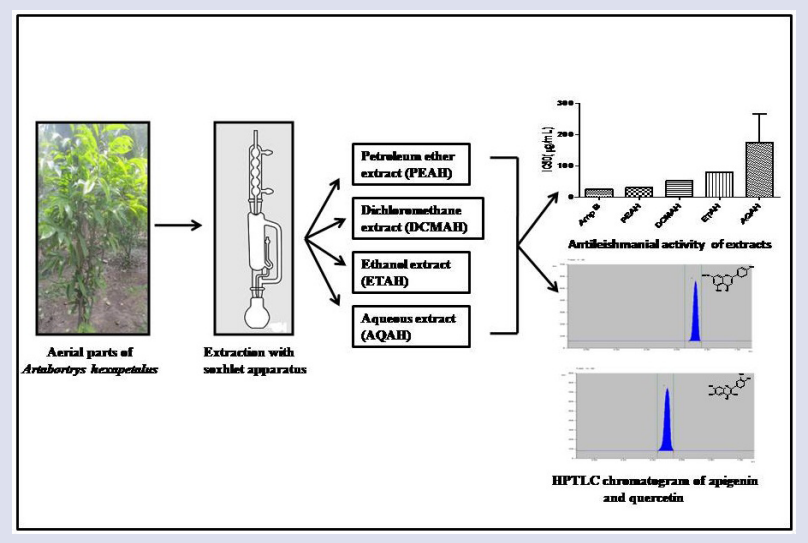

19. Bajaj S, Wakode S. Pharmacognostical evaluation and anthelmentic activity of Swertia alata royle; 8(8):3315-24

20. Kirtikar KR, Basu BD. Indian medicinal plants, Int. book distributors, Dehradun. India. 2006;2:1667.

21. Medda S, Mukhopadhayay S, Kumar B. Evaluation of the in vivo activity and toxicity of Amarogentin, an antileishmanial agent, in both liposomal and niosomal forms. J Antimicrobial. Chem. 1999;44(6):791-4.

22. Parveen R, Ahmad FJ, lqbal Z, Singh M. Simultaneous estimation of anticancer terpenoids in pharmaceutical Nanoformulation by RP-HPLC and HPTLC. Acta Chromatographica. 2014;26(2):391-400.

23. KamalYT, Musthaba SM, Singh M. Development and validation of HPLC method for simultaneous estimation of piperine and guggulsterones in compound unani formulation (tablets) and a nano reservoir system. Biomedical Chromatography. 2012;26(10):1183-90.

24. Manchanda S, Sahoo PK, Majumdar DK. RP-HPLC method development and validation for the estimation of Acetazolamide in bulk drug and formulations with forced degradation. Der Pharmacia Lettre. 2016;8(1):338-47.

25. Tobie EJ, Brand TV, Mehlman B. Cultural and physiological observations on Trypanosoma rhodesiense and Trypanosoma gambiense. J Parasitology. 1950;36(1):48-54.

26. Qureshi N, Rahman UH, Ali A, Khan I. In vitro Evaluation of the Anti-Leishmanial Activity of Euphorbia Helioscopia Stem Extract in Comparison with Synthetic Drug Amphotericin B, Asian Journal of Natural and Applied Sciences. 2014;3(3):12-17.

27. Kigondu EV, Rukunga GM, Keriko JM, Tonui WK, Gathirwa JW, Kirira PG, et al. Anti-parasitic activity and cytotoxicity of selected medicinal plants from Kenya. J. Ethnopharmacology. 2009;123(3):504-9.

28. Sharma U, Velpandian, T, Sharma P, Singh S. Evaluation of antileishmanial activity of selected Indian plants known to have antimicrobial properties. Parasitology Res. 2009;105(5):1287-93.

29. Ali N, Ahmed G, Shah SWA, Shah I, Ghias M, Khan I. Acute toxicity, brine shrimp cytotoxicity and relaxant activity of fruits of callistemon citrinus curtis Bio Med Central Complementary and Alternative Medicine. 2011;11(1):99.

30. Bongo M, Loiseaum N, Lawrence PM, Bories FC, Craciunescu DG, Robert-Gero M. In vitro sensitivity of Leishmania donovani to organometallic derivatives of pentamidine. Parasitology Research. 1997;83(5):515-7.

31. Benjamin CL, German GR. Students study guide microbiology: concepts and application. McGrow-Hill Book company. 1993:248-54.

32. Cory AH, Owen TC, Barltrop JA, Cory JG. Use of an aqueous soluble tetrazolium/formazan assay for cell growth in culture. Cancer Communications. 1991;3(7):207-12.

33. Mossman T. Rapid colorimetric assay for cellular growth and survival: application to proliferation and cytotoxicity assays. J Immunological Methods. 1993; 16(1-2):55-63.

34. Bisht D, Gupta M, Srivastava S, Datt B, Rawat AKS. Comparative Pharmacognostic Evaluation of Three species of Swertia L. (Gentianaceae), Pharmacognosy Journal. 2011; 3(19):7-12

35. Sadeghi NB, Saki J, Khademvatan S, Nanaei S. In vitro antileishmanial activity of the medicinal plant-Satureja khuzestanica jamzad. journal of medicinal plants research. 2011;5(24):5912-5.

36. Fournet A, Munoz V. Natural Products as Trypanocidal, Antileishmanial and Antimalarial Drugs. Current Topics in Medicinal Chemistry. 2002;2(11):1215-37.

37. Torres-Santos EC, Lopes D, Oliveira RR, Carauta JP, Falcao CA, Kaplan MA, et al. Antileishmanial activity of isolated triterpenoids from Pourouma guianensis, Phytomedicine. 2004;11(2-3):114-20.

\section{SUMMARY}

- High yield of extracts were obtained from hot extraction method.

- The newly developed and validated HPTLC method was applied for the simultaneous estimation of oleanolic acid and swertiamarin in various extracts of S.alata.

- All the extracts had shown antileishmanial activity against $L$. donovani but the ethanolic fraction of $S$. alata was found to be good among them. 


\section{ABOUT AUTHORS}

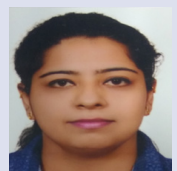

Sakshi Bajaj: Is a doctoral student at University of Delhi (DU). She has done Master degree in Pharmacognosy and Phytochemistry. Her doctoral research focused on standardization, Isolation, HPTLC analysis and evaluation of antioxidant, anti-inflammatory, anthelmentic and cytotoxicity of natural products.

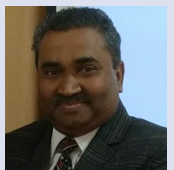

Dr. Sharad Wakode: Obtained his PhD degree in 2004 from Rajiv Gandhi Prodyogiki Vishwavidyalaya under the supervision of Prof. S.G.Kaskhedikar. Currently, he is positioned as Associate Professor at the Department of Pharmaceutical Chemistry, Delhi Institute of Pharmaceutical Sciences and Research (now known as Delhi Pharmaceutical and Research University), New Delhi. Dr. Wakode is working on various research projects in the field of pharmaceutical chemistry sponsored by esteemed agencies such as DST and AICTE.

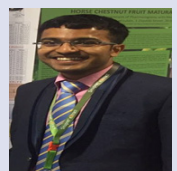

Washim Khan: Is a Doctoral Student at Department of Pharmacognosy and Phytochemistry, Faculty of Pharmacy, Jamia Hamdard (JH), where he graduated in Master of Pharmacy in Pharmaceutical Biotechnology. His doctoral research focused on HPLC, HPTLC and G-MS metabolomics of natural products. He has published more than 14 publications in international journals.

Cite this article: Bajaj S, Wakode S, Khan W. HPTLC Analysis and Antiproliferative Effect of Various Extracts of Swertia alata on Growth of Leishmania donovani Promastigotes in vitro. Pharmacog J. 2017;9(6)Suppl:s107-s16. 